\title{
A long-term ecstasy-related change in visual perception
}

\author{
John Brown • Mark Edwards • Elinor McKone • \\ Jeff Ward
}

Published online: 19 June 2007

(C) Springer-Verlag 2007

We would like to advise the legend of Fig. 3 in our original article was incorrectly labeled. The labels for the "Ecstasy users with recent amphetamine use" and "Ecstasy users abstinent from amphetamines" were reversed. The label for the vertical axis was also omitted. The corrected Fig. 3 is printed below.

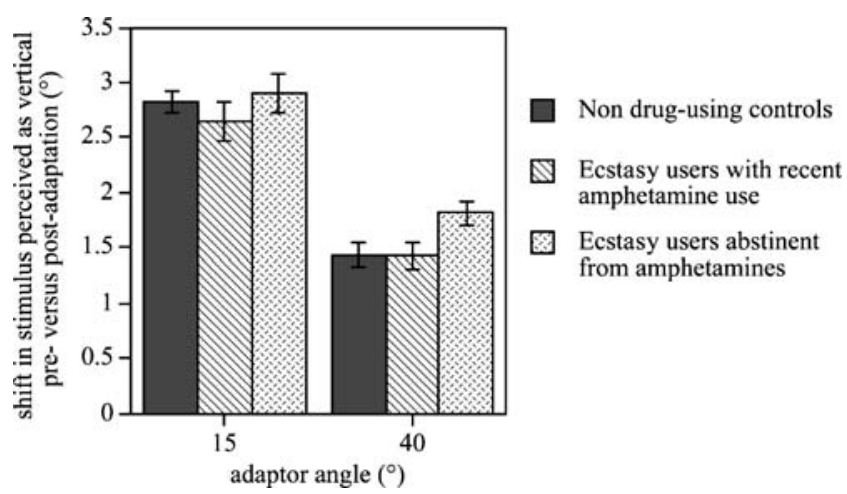

Fig. 3 Size of the tilt aftereffect for controls and ecstasy users split into subgroups of those abstinent from amphetamines for at least 115 days, and those using amphetamines recently (within 61 days). Error bars show \pm 1 SEM

The online version of the original article can be found at http://dx.doi. org/10.1007/s00213-007-0785-0.

J. Brown $(\bowtie) \cdot$ M. Edwards $\cdot$ E. McKone $\cdot$ J. Ward

School of Psychology, The Australian National University,

Building 39,

Canberra 0200, Australia

e-mail: john.brown@anu.edu.au 